\title{
Multimode Traffic Travel Behavior Characteristics Analysis and Congestion Governance Research
}

\author{
Wen Li $\left(\mathbb{D},{ }^{1}\right.$ Wei Feng, ${ }^{2}$ and Hua-zhi Yuan ${ }^{2}{ }^{2}$ \\ ${ }^{1}$ School of Automobile, Chang'an University, Xi'an, Shaanxi 710064, China \\ ${ }^{2}$ School of Civil Engineering, Lanzhou University of Technology, Lanzhou, Gansu 730050, China \\ Correspondence should be addressed to Hua-zhi Yuan; 41810670@qq.com
}

Received 15 October 2020; Revised 2 November 2020; Accepted 12 November 2020; Published 26 November 2020

Academic Editor: Zhongxiang Feng

Copyright (C) 2020 Wen Li et al. This is an open access article distributed under the Creative Commons Attribution License, which permits unrestricted use, distribution, and reproduction in any medium, provided the original work is properly cited.

\begin{abstract}
The rapid aggregation of modern urban population and the rapid growth of car travel lead to traffic congestion, environmental pollution, and other problems. In view of the limited land resources in our country, it is impractical to meet residents' travel demand by blindly increasing traffic supply. Therefore, addressing the urban road congestion problem for sustainable development of modern cities, the paper makes research on residents' travel behavior characteristics and travel preference under the condition of multimodal transportation to formulate reasonable traffic demand management strategy for the guide on public traffic demand, bus priority strategy, and congestion management. The operation characteristic of each transportation mode is analyzed by comparing its related traffic and economic characteristics. Multimode traffic choice behavior is discussed by establishing multiple logistic regression models to analyze the main influencing factors to travelers' social and economic attributes, travel characteristics, and preference based on travel survey data of urban residents. The paper proposes the development of an urban public transportation system and travelling mode shift from cars to public transportation as reasonable travel structure for congestion management and sustainable development of modern cities.
\end{abstract}

\section{Introduction}

Composed of various traffic modes such as car, bus, and subway and different and mutual influencing parts for the system's coordination and stability including pedestrians, vehicles, roads, environment, and other elements, modern urban traffic in China is considered as the basic condition for the city's rapid and stable development and is meeting people's increasing traffic demands to certain extent [1]. However, due to mismatch between existing traffic supply and demand caused by continuous increase of car ownership, traffic congestion has become an increasingly acute problem and a major bottleneck hindering the sustainable development of the society and severely influencing urban residents' life quality [2]. At present, all over the world, both developed and developing countries are trying to find solutions to the severe problem and challenge of traffic congestion.

Urban road congestion is often shown as frequent largescale overcrowded traffic plus traffic stagnation in main road intersections and key road sections [3]. The congestion situation is getting even more acute with further city construction. At present, traffic congestion is tending to expand to external regions of central areas of large cities and metropolitan areas and has gradually become normal in some small- and medium-sized cities $[4,5]$. According to statistics, traffic congestion has become problem in more than $60 \%$ of China's 655 cities with different degrees throughout the day, especially in morning and evening rush hours, brought much inconvenience to people's life, such as delay travel time and increase in travel costs, and therefore, brought a negative impact on the urban traffic environment. Although in recent years, due to continuous increase in urban transportation infrastructure to improve transportation network and supply, according to Downs' Law, new road facilities will lead to new road demand, and the traffic demand always tends to be higher than the traffic supply [6]. Therefore, large-scale construction of traffic infrastructure alone could hardly provide a fundamental 
solution to urban traffic problems. With the development of urban traffic in China to a certain extent, traffic demand management plays an increasingly important role in traffic planning.

Traffic demand management (TDM) intends to achieve stable and healthy balance of the traffic system by providing guidance and limits of travel behavior, adjust residents' trip distribution, and alleviate contradiction between supply and demand of traffic so as to realize the set target of traffic system operation efficiency improvement, congestion ease, and pollution reduction with the comprehensive execution of various policies, laws, and regulations, as well as economic measures. An effective TDM strategy needs to consider the change of travelers' socioeconomic attributes and travel demands based on transportation system attributes [7, 8]. Given the comparatively bigger conflict between urban transportation structure and network, it is necessary to make investigation on urban residents travel behavior characteristics to find the existing problem in urban transportation structure and formulate corresponding traffic demand management measures so as to improve people's travel quality, effectively relieve urban traffic congestion, and realize sustainable development of economy, society, and environment $[9,10]$.

With the deepening of theoretical research on travel behavior, experts and scholars began to elaborate the characteristics and mechanism of residents' travel choice behavior from multiple perspectives [11, 12]. Residents' choice of an all-day travel mode is changeable. By taking dynamic factors into consideration, they established a dynamic model of traveler mode selection and verified the accuracy of the model through case analysis. It is found that the previous travel mode of residents will have a certain influence on the travel choice of this time and the travel mode of the main chain will have a certain influence on the subchain selection results [13]. A hierarchical logit model is used to begin their research with the morning and evening peak stage travel chain of the travel process analysis to describe urban residents' interchanging mode choice behavior in direct driving, subway and parking, investigate travel mode choice and subway fare levels and parking charge strategy under different operating mechanism based on elastic demand balance equation, and reach the conclusion that the increase in parking fees and reduction of subway fares help to attract travelers choosing public transit as the travel mode [14].

\section{Resident Travel Survey Results Analysis}

In this paper, a questionnaire survey was used. A total of 60 people filled in the questionnaire. After screening, 58 valid questionnaires were sent, and the effective rate is $96.67 \%$.

2.1. Gender, Age, and Occupation. The survey results show that there are more females than males among the respondents, with 28 males accounting for $48.28 \%$ and 30 females accounting for $51.72 \%$ [15]. The age distribution of the respondents showed a concentrated trend, with the young and middle-aged accounting for the largest proportion (98.28\%), constituting the main body of travel. The occupations of the respondents are mainly students and employees in enterprises, accounting for $37.93 \%$ and $31.03 \%$, respectively, followed by school/medical institution personnel, accounting for $10.34 \%$ (see Figure 1).

2.2. Family Monthly Income. The family income data mainly reflect the economic conditions of the respondents' families $[16,17]$. Families with relatively good economic conditions and high income tend to have higher requirements for travel choices. Such preference is also related to various factors such as residents' consumption concepts and psychological states. In contrast, families with average economic conditions tend to give more consideration to travel costs. There are certain differences in travel choices in these two groups (see Figure 2).

2.3. Family Car Ownership. Car ownership is very important information in the traveler's family attribute. The results of the survey (Figure 3 and Figure 4 ) show that $51.72 \%$ of the respondents have a car available at home, $6.9 \%$ of the respondents have 2 or more cars at home, and these travelers basically travel by car or taxi. Therefore, how to transfer this group of travelers from cars to public transport is considered to be the first problem in solving congestion.

\section{Analysis of Residents' Travel Preferences}

In the analysis of urban residents' travel habits and preferences, a Likert scale of 5 scales was adopted in the questionnaire, with the score ranging from 1 to 5 points, to understand residents' attitudes toward travel. The Cronbach coefficient method was used to test the reliability, and the kronbach coefficient was 0.759 , indicating high consistency of the scale and reliable data analysis results.

At the same time, in order to clarify the concept that all variables in the scale are not the same, the KMO and Bartlett spherical test were carried out in this paper (Table 1), where the $\mathrm{KMO}$ value is 0.657 , and it is generally believed that the KMO value greater than 0.5 is suitable for factor analysis. The Sig. Value $0.00<0.05$ indicates that Bartlett spherical test results are significant.

Based on the analysis of the results of the scale, the following conclusions can be drawn about residents' travel preferences:

(1) The average score of the first three questions is 4.03 , which indicates that purpose, time requirement, and number of transfer times of travelling significantly influence residents in route selection.

(2) Residents' public transportation mode travel experience determines their travel behavior to a certain extent. Good user experiences represent possible preference towards the corresponding travel mode. The investigation results show that residents are not satisfied with the current level of public transport service and routes accessibility, as the average scores 


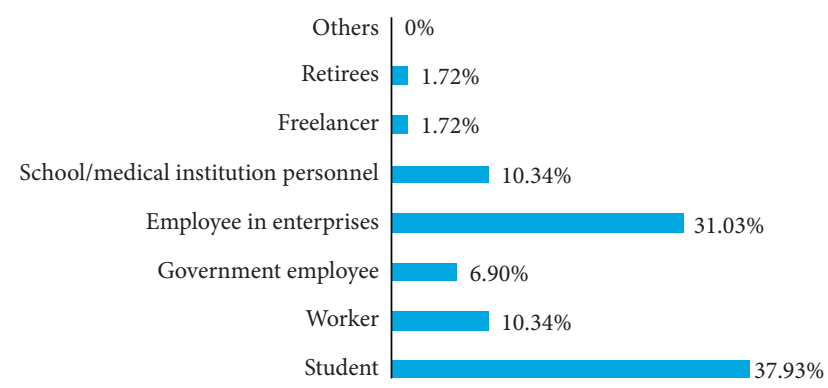

FIgURE 1: Occupational distribution of respondents.
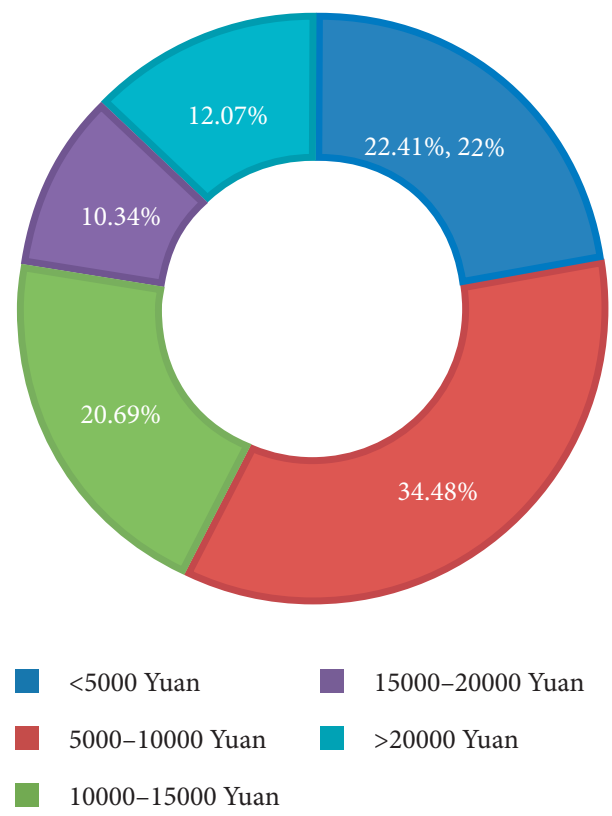

FIgURE 2: Distribution of monthly income of respondents' families.

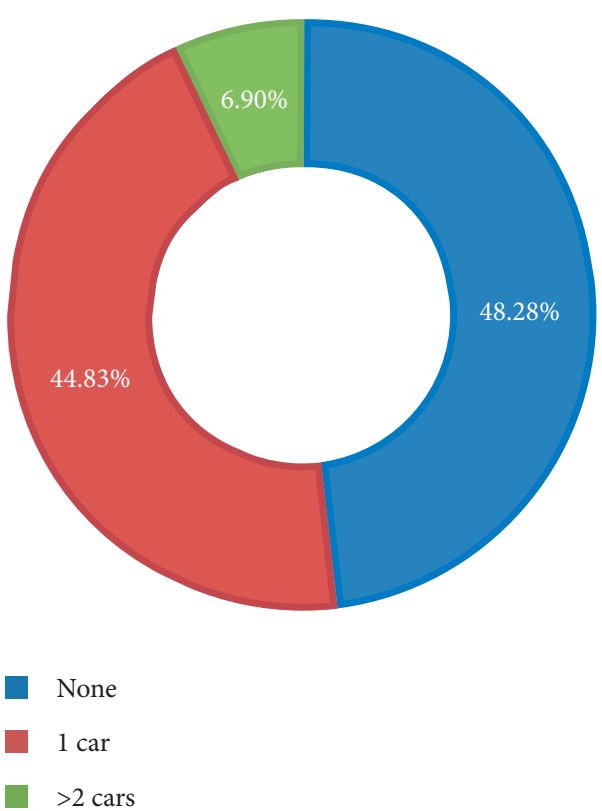

FIGURE 3: Distribution of car ownership among respondents' families. of related questions are less than 3 points, which indicates that public transport needs to be further improved in development level.

(3) Though traveler's demand for car use is a rigid one, it could be lowered down via certain economic measures. More than $50 \%$ of the respondents agree that the parking fees range is a factor that influences car travel preference, and 54\% are "more willing to choose public transportation to travel to the city centre," Therefore, increasing parking fees could play certain role in providing rational guide on car travelling.

\section{Travel Mode Selection}

When selecting transportation modes, travelers consider not only their own social and economic attributes and specific travel characteristics but also service attributes of various transportation modes, namely, comfort, accessibility, and safety. There are many factors affecting the behavior of travel mode selection. This paper analyzes the travel characteristics of urban residents and the way how some objective factors influence influencing travel mode selection based on the related questionnaire.

4.1. Model Description. The multinomial logistic regression model is a statistical analysis method used to study the relationship between multiple categorical variables and their influencing factors. This section, while making analysis on influencing factors of travel mode choice, regards travel mode choice as dependent variables. As there is not order relation among the various categories, multiple values are defined to describe different choices, with 1-7 indicating different travel modes, namely, correspondently as walking, bicycling, car, taxi, bus, subway, and other travel mode choice. Travel mode selection is considered as independent variables and influencing factors. With selection No. 1 (walking) as reference option to calculate multinomial logistic regression, the factors influencing travel mode choice are calculated.

In the statistical analysis software SPSS, through Analyze to Regression, the multinomial logistic module can be used to make multiple logistic regression analysis.

4.2. Analysis of Travel Influencing Factors. This section studies the influence factors of travel mode choice, given the limitations of sample data, and only 5 personal attributes such as sex, age, family property, the number of cars, and travel properties (travel distance) are considered as influencing factors (see Table 2). In order to ensure the individual factors of parameter estimate results pass the inspection and to prevent the special data affecting regression results, some influencing factors are grouped as follows:

The age groups are divided into four groups according to the general age groups of students, workers, and retirees, 1 : 25 under, $2: 25-45$ between, $3: 46-60$, and $4: 60$ above.

The monthly household income is roughly divided into 5 groups, which are 1:500 yuan less than $2: 5000-10000$ yuan, 


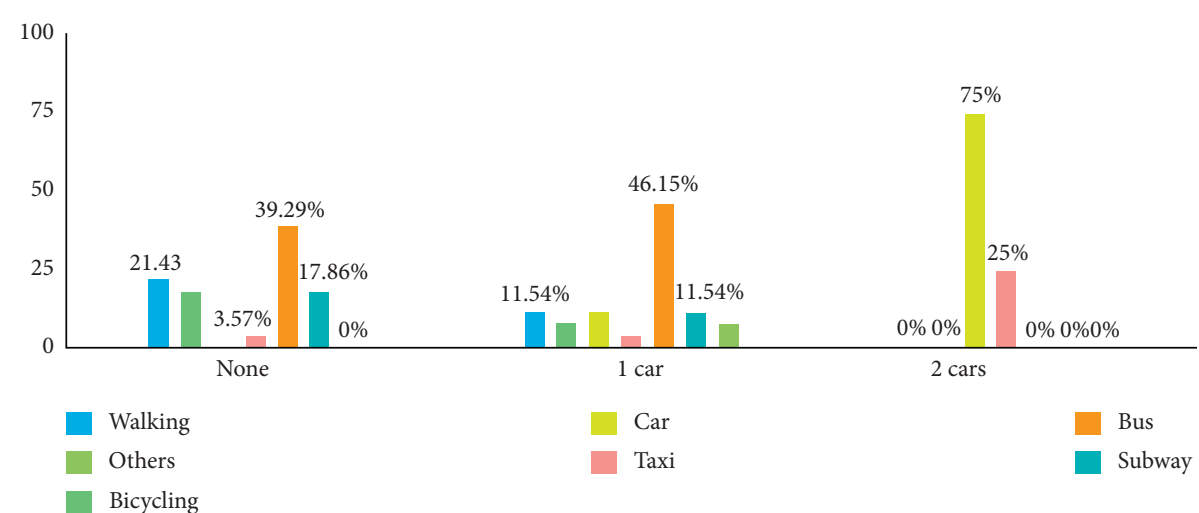

Figure 4: Cross distribution diagram of car ownership and travel mode selection of respondents' family.

TABLE 1: Test results of the KMO and Bartlett test.

\begin{tabular}{lcc}
\hline The sampling fitness of KMO & 0.657 & \\
\hline & Approximates chi- & 229.951 \\
Bartlett sphericity test & square & 45 \\
& Degrees of freedom & Significant \\
& & 0.000 \\
\hline
\end{tabular}

3:10000-15000 yuan, 4:15000-20000 yuan, and above 5: 20000 yuan.

Travel distance was divided into 5 groups: $1: 0-3 \mathrm{~km}, 2$ : 4-6 km, 3: 7-9 km, 4: 10-12 km, and 5: $12 \mathrm{~km}$ above.

\subsection{Parameter Estimation and the Accuracy Test of the Model.} When parameter estimation is carried out for multiple logistic regression models, taking walking as the reference object, parameter estimation results of other transportation modes relative to walking are obtained, as shown in Table 3.

In this paper, the following indexes are mainly considered when testing the accuracy of the model.

4.3.1. Model Fitting Information. The model fitting information shown in Table 4 indicates whether the model is capable of making accurate predictions. Through calculation and analysis, the overall significance level of the model is $<0.05$, so the overall fitting degree of the model is good.

4.3.2. Likelihood Ratio Test. The likelihood ratio test is to check whether each predictive variable works on the model. According to the results of multiple logistic regression analysis in Table 5, the factors whose probability is less than a given significance level ( $=0.05$ in this paper) in the likelihood ratio test are family monthly income, family car ownership, and travel distance, which have a significant impact on residents' travel mode selection behavior.

Further analysis of the abovementioned factors shows that travelers with lower family income tend to choose lowcost means of transportation such as walking, bicycles, and buses. With the growth of income, the residents have gradually transformed into high-quality travel modes such as subway and taxi. When the income increases further, the proportion of private car travel increases sharply. Most of the respondents who did not have a car at home used public transportation such as bus and subway. When the number of cars at home is not zero, travelers choose more convenient and fast cars. According to the survey, when judging whether to travel by car, residents first consider the travel distance, travel purpose, and whether they have family members and children. Compared with public transportation, cars are more immune to weather, travel distance, and other factors, and cars are more comfortable. The longer the travel distance, the greater the possibility of choosing a private car. On the contrary, in the flexible travel with short travel distance, residents prefer more green travel modes, such as walking, bicycle, and other slow traffic.

\section{Discussion}

Optimization of travel structure includes not only adjusting the growth rate of different transportation modes to change their proportion in the travel structure but also the transformation of main transportation modes in the travel structure. In terms of the optimization of urban travel structure, government policy orientation and market orientation should be combined to strengthen the guidance of residents' choice of travel mode, so as to improve the efficiency of urban traffic and ensure the effective implementation of TDM strategy.

Through the investigation and analysis of the travel situation of urban residents, it is found that every time a traveler travels, there is still some unreasonable travel mode selection, which leads to the consumption of unnecessary travel time and travel cost and causes urban congestion and environmental pollution and other problems [17]. Based on residents' travel behavior characteristics and the analysis of the corresponding causes, this section proposes the improvement measures of congestion to strengthen urban traffic operation adjustment of the system and promote efficient, convenient, safe, and comfortable public transport system to reach target of development of transportation structures section for multimodal transportation.

5.1. Ensure Public Transport Goes First. In the urban road traffic system, each traffic mode presents different demands for road space transportation and produces different 
TABLE 2: Analysis of influencing factors of residents' choice of travel mode.

\begin{tabular}{lcc}
\hline Factor attributes & Influence factors & Note \\
\hline Personal attribute & Gender & 1: male 0: female \\
& Age & Divided into four groups in order; the value is 1-4 \\
\hline Family attribute & Family monthly income & Divided into five groups in order; the value is 1-5 \\
& Number of private cars & 1: no 2: 1 3: 2 or more \\
\hline Travel characteristics and attributes & Travel distance & Divided into five groups in order; the value is 1-5 \\
\hline
\end{tabular}

TABle 3: Parameter estimation results.

\begin{tabular}{lcccccccccc}
\hline $\begin{array}{l}\text { Way to travel } \\
\text { Influential factors }\end{array}$ & \multicolumn{2}{c}{$\begin{array}{c}\text { Bicycle } \\
\text { S }\end{array}$} & \multicolumn{2}{c}{ Car } & \multicolumn{2}{c}{ Taxi } & \multicolumn{2}{c}{ Bus } & \multicolumn{2}{c}{ Subway } \\
Gender & 1.49 & 0.45 & 0.52 & 0.99 & 1.77 & 0.99 & 0.66 & 0.65 & 0.67 & 0.65 \\
Age & 34.18 & 0.00 & -17.92 & 0.99 & 59.22 & 0.99 & 22.76 & 0.00 & 12.04 & 0.00 \\
Family monthly income & 24.72 & 0.92 & 8.26 & 0.97 & -23.23 & 0.94 & 16.90 & 0.88 & 23.91 & 0.95 \\
Family car number & -9.13 & 0.99 & 43.05 & 0.97 & -75.33 & 0.99 & 2.85 & 0.002 & 6.05 & 0.96 \\
Travel distance & 8.56 & 0.97 & 19.65 & 0.95 & 23.79 & 0.97 & -2.09 & 0.98 & -5.67 & 0.98 \\
\hline
\end{tabular}

TABLE 4: Model fitting information.

\begin{tabular}{lcccc}
\hline Model & Model fitting condition-2 logarithmic likelihood & $\begin{array}{c}\text { Chi- } \\
\text { square }\end{array}$ & Likelihood ratio to test the degree of freedom Significance \\
\hline Intercept only & 190.304 & 136.866 & 84 & 0.000 \\
Final & 53.439 & 139 & 84 \\
\hline
\end{tabular}

TABLE 5: Likelihood ratio test.

\begin{tabular}{lccc}
\hline Effect & Chi-square & Likelihood ratio test & The degree of freedom significance \\
\hline Intercept & 0.000 & 0 & 0.996 \\
Gender & 0.599 & 526 & 0.108 \\
Age & 25.665 & 18 & 0.042 \\
Monthly household income & 37.213 & 24 & 0.006 \\
Family car ownership & 27.952 & 12 & 0.016 \\
Travel distance & 41.273 & 24 & \\
\hline
\end{tabular}

environmental pollution [18]. It is an important task for urban traffic structure optimization as the primary way to solve congestion problem. In essence, the public transport priority policy is an induction strategy, that is, to guide residents to shift from a car mode to a public transport mode. Therefore, the intensity of public transport infrastructure construction should be continuously increased to create a good external environment for the development of public transport. With priority on the bus in the urban road, bus lanes effectively improve the speed of the bus and accessibility. The relevant data show that since the opening up of bus lanes, Chengdu bus average operating speed increased from $13.5 \mathrm{~km} / \mathrm{h}$ to $19.3 \mathrm{~km} / \mathrm{h}$, increased by $42.96 \%$, significantly improved overall operating efficiency of public transport, to enhance the public transportation way to attract residents, and achieved good social benefits and economic benefits. Therefore, the government should speed up the construction of bus lanes, arrange the layout of line network, change the station facilities, and promote the formation of urban bus lanes, thus reducing the space for other social vehicles to travel [19].

In addition to the priority of space, bus signal priority should also be considered. Bus lane exclusive priority signal control to the bus vehicles at intersections, as a temporary signal control scheme, makes it possible for buses to pass through the intersections quickly without affecting overall traffic operation, reduce time delay caused by traffic jam, and attract bus passenger flow. Therefore, it plays important role in improving the bus service level and traffic structure.

5.2. Make the External Cost of Private Car Travel an Internal One. External cost, namely, externality, refers to the economic loss caused by individual behavior to others and the society. As one part of external cost, private cars' influence on city environment and road resources, namely, traffic congestion, accidents, and environmental pollution, occupies high proportion of total travel cost which has to be 
shared by not only car owners but also the whole society, and it will lead to traffic contradictions in the long run when the high increase of private car users goes beyond reasonable traffic capacity [20].

The internalization of external costs is to improve the utilization of road resources by making private car travelers understand and bear all the social costs caused by themselves. At present, the research of the internalization of external costs for private cars and economic management is widely adopted, that is, from affecting the costs and benefits of using private cars, using the price mechanism, the private cars of different travel behavior incentive and restrictive measures, respectively, guide the private car owners travel choice of rationalization, so as to promote the external cost reduced.

The government can internalize it by taxation and fees increase such as raising fuel prices and levies fuel taxes to raise the travel cost of private cars. Congestion fees will be levied on vehicles driving on congested roads according to their vehicle types to reduce the frequency of private cars $[21,22]$. Furthermore, uplifting of parking fee level in downtown area could reduce urban traffic pressure.

The abovementioned measures limit the growth of the number of cars by means of economic leverage and reasonably guide on travel so as to optimize the travel choice of travelers.

5.3. Improve the Use Efficiency of Taxis. Taxis play an important role in urban traffic because of their flexibility and convenience. However, the sharing rate of taxis is still insufficient, due to the low enthusiasm of taxi enterprises and individuals and the contradiction between taxi volume and congestion [23]. If the capacity is insufficient, people's travel needs will not be met. Therefore, some people may turn to cars to travel, which will aggravate the road congestion. However, if the current situation of congestion is not well solved, increasing taxi capacity is likely to lower operating efficiency.

Therefore, it is urgent to determine the reasonable scale of taxi and improve the service quality of taxi. Under the guidance of the government, the links between taxi enterprises can be strengthened through the integration of resources and technologies to promote healthy competition among enterprises. At the same time, the emergence of the online car-hailing triggers the operation mode of the new taxi industry and improves the operating efficiency of the existing taxi. Therefore, the way to improve the share rate of taxi in urban transportation system required the ability to seize opportunity, improve service quality, and development of diversified services as follows: strengthening the online hailing platform network, promoting rational planning to control private car numbers, and to satisfy different levels marketed.

5.4. Focus on Transfer System Construction. To limit parking demand by raising parking fees in the central area is a simple means of restraining. It is undeniable that it will have an impact on the economic development of the downtown area, and the root of easing congestion lies in really encouraging travelers to turn to the public transportation mode with large volume [24]. Therefore, we should pay attention to the construction of the transfer system. Transfer refers to the connecting transfer of various urban transportation modes, involving buses, subways, taxis, cars, and bicycles. The key is to shorten the walking distance and strengthen the coordination between ground transportation, so that passengers can realize convenient transfer in a relatively short time $[25,26]$.

The rapid development of subway provides safe, reliable, convenient, and comfortable transportation services for the city. However, due to its large investment, long cycle, impossible coverage to reach $100 \%$, and limited service areas, the key to optimize the transportation system is to strengthen the effective connection between subway and other transportation modes. Park-and-transfer is one of the forms $[27,28]$. The survey shows that more than half of the people have park-and-transfer experience, which indicates that park-and-transfer has become one of the important travel options for residents. P\&R models are used to take individual vehicles, such as cars and bicycles, to park-andride points to transfer public transport into the city centre. In areas where traffic is heavy, $\mathrm{P} \& \mathrm{R}$ models have obvious advantages. The key lies in the parking of vehicles. Therefore, the planning and design of parking and transfer facilities should be strengthened at urban transfer points, and the parking lots for motor vehicles and bicycles should be built. Meanwhile, the transfer distance should be reduced, and the connection between transfer lines should be enhanced, so as to expand the service scope of subway and promote the travelers to choose transfer travel.

\section{Conclusions}

The rapid concentration of population in modern cities and the rapid growth of car travel have led to traffic congestion, environmental pollution, and other problems. In view of the limited land resources in our country, it is unrealistic to blindly increase traffic flow to meet residents' travel needs. Therefore, in view of the urban road congestion problem of the sustainable development of modern cities, the characteristics of residents' travel behavior and travel preferences under multimode conditions are studied, and reasonable traffic demand management strategies are formulated to guide public transportation demand, bus priority strategies, and congestion management. We analyze the operating characteristics of each mode of transportation by comparing its related traffic and economic characteristics. Through the establishment of multiple logistic regression models to discuss the multimodal transportation choice behavior, based on urban residents' travel survey data, the main factors affecting the socioeconomic attributes, travel characteristics, and preferences of travelers are analyzed. The policies proposed in this study include guaranteeing public transport travel, guiding the internalization of the external costs of private car travel, proposing the efficiency of taxi use, and focusing on the construction of transfer systems. The study found that respondents believe that compared to public 
transportation, cars are less affected by factors such as weather and travel distance and more comfortable. This will promote the increase in the use of cars by travelers, thereby increasing the level of urban traffic congestion. The policy proposed in this study can solve this problem well.

\section{Data Availability}

The data used to support the findings of this study are available from the corresponding author upon request.

\section{Conflicts of Interest}

The authors declare that they have no conflicts of interest.

\section{References}

[1] Y. Han, T. Zhang, and M. Wang, "Holiday travel behavior analysis and empirical study with integrated travel reservation information usage," Transportation Research Part A: Policy and Practice, vol. 134, 2020.

[2] B. Wang, C. Shao, J. Li, J. Weng, and X. Ji, "Holiday travel behavior analysis and empirical study under integrated multimodal travel information service," Transport Policy, vol. 39, pp. 21-36, 2015.

[3] X. Hua, Study on Optimization of Travel Structure of MultiMode Transportation System Based on Supply-Demand Balance, Southeast University, Nanjing, China, 2016.

[4] H. Hu, X. Yang, J. Teng et al., "Study on travel mode choice behavior with integrated multi-modal transit information service," in Proceedings of the Eighth International Conference of Chinese Logistics \& Transportation Professionals, Breckenridge, CO, USA, 2009.

[5] D. H. Li and W. G. Hua, Disaggregate Logit Model of Public Transportation Share Ratio Prediction in Urban City, Springer, Berlin, Germany, 2011.

[6] X. Hu and J. Lu, Traffic Travel Choice Behavior Analysis and Traffic Demand Management, Vol. 12, Southeast UniversityPress, Nanjing, China, 2014.

[7] K. Park and Y. Reisinger, "Differences in the perceived influence of natural disasters and travel risk on international travel," Tourism Geographies, vol. 12, no. 1, pp. 1-24, 2010.

[8] H.-P. Park and D. Hoon, "A study on how the perceived danger and travel experience influence the decision-making process of tourists where they want to visit," International Journal of Tourism and Hospitality Research, vol. 14, pp. 3566, 2001.

[9] Y. Wang, B. Shen, H. Wu et al., "Modeling illegal pedestrian crossing behaviors at unmarked mid-block roadway based on extended decision field theory," Physica A, vol. 562, 2021.

[10] Y. Wang, Z. Yao, C. Wang, J. Ren, and Q. Chen, “The impact of intelligent transportation points system based on elo rating on emergence of cooperation at y intersection," Applied Mathematics and Computation, vol. 370, Article ID 124923, 2020.

[11] U. Yavas, "Foreign travel behaviour in a growing vacation market: implications for tourism marketers," European Journal of Marketing, vol. 21, no. 5, pp. 57-69, 2007.

[12] U. Yavas, "Foreign travel behaviour in a growing vacation market: implications for tourism marketers," European Journal of Marketing, vol. 21, no. 5, pp. 57-69, 1987.
[13] W. Xia, W. Wang, and J. Chen, "Research on dynamic model of residents' choice of whole-day travel mode," Chinese Journal of Highways, vol. 25, no. 02, pp. 121-126, 2012.

[14] X. Lu, H. Huang, T. Liu et al., "Considering the travel mode selection and pricing mechanism of morning and evening peak travel chain," Systems Engineering Theory and Practice, vol. 33, no. 1, pp. 167-174, 2013.

[15] F. S. Koppelman, C. R. Bhat, and J. L. Schofer, "Market research evaluation of actions to reduce suburban traffic congestion: commuter travel behavior and response to demand reduction actions," Transportation Research Part A: Policy and Practice, vol. 27, no. 5, pp. 383-393, 1993.

[16] L. Zhang, G.-L. Chang, S. Zhu et al., "Integrating an agentbased travel behavior model with large-scale microscopic traffic simulation for corridor-level and subarea transportation operations and planning applications," Journal of Urban Planning and Development, vol. 139, no. 2, pp. 94-103, 2013.

[17] T.-Q. Tang, K.-W. Xu, S.-C. Yang, and C. Ding, "Impacts of soc on car-following behavior and travel time in the heterogeneous traffic system," Physica A: Statistical Mechanics and its Applications, vol. 441, pp. 221-229, 2016.

[18] A. Jonathan, R. Ward, Eddie, and Wilson, "Criteria for convective versus absolute string instability incar-following models," Proceedings of the Royal Society A: Mathematical, Physical and Engineering Ences, vol. 467, no. 2132, pp. 2185-2208, 2011.

[19] T. Oguchi, "Travel behavior model and dynamic traffic simulation toward its society. analysis of bottleneck phenomena at basic freeway segments. Car-following model and future exploration," Doboku Gakkai Ronbunshu, vol. 660, pp. 39-51, 2000.

[20] Z. Feng, J. Zhan, C. Wang, C. Ma, and Z. Huang, "The association between musculoskeletal disorders and driver behaviors among professional drivers in China," International Journal of Occupational Safety and Ergonomics, vol. 26, no. 3, pp. 551-561, 2020.

[21] Y. Shen, H. Dong, L. Jia et al., "A method of traffic travel status segmentation based on position trajectories," in Proceedings of the IEEE International Conference on Intelligent Transportation Systems, IEEE, Gran Canaria, Spain, 2015.

[22] C. Wang, W. H. Zhang, Z. X. Feng, K. Wang, and Y. H. Gao, "Exploring factors influencing the risky cycling behaviours of young cyclists aged 15-24 years: a questionnaire-based study in China," Risk Analysis, vol. 40, no. 8, pp. 1554-1570, 2020.

[23] D. Q. Nguyen-Phuoc, G. Currie, C. De Gruyter, I. Kim, and W. Young, "Modelling the net traffic congestion impact of bus operations in Melbourne," Transportation Research Part A: Policy and Practice, vol. 117, no. 10, pp. 1-12, 2018.

[24] H. Ding, M. Yang, W. Wang et al., "Simulating and analyzing the effect on travel behavior of residential relocation and corresponding traffic demand management strategies," KSCE Journal of Civil Engineering, vol. 22, no. 2, pp. 837-849, 2018.

[25] Pinnelas and Sharon, Traffic Now, Transit Later: Understanding Current and Future Travel Behavior of Residents in Active-Adult Communities, Rutgers University, New Brunswick, NJ, USA, 2011.

[26] Z. C. Juan and J. C. Xianyu, "Research on activity-travel decision behavior with effect of traffic information," Zhongguo Gonglu Xuebao/China Journal of Highway and Transport, vol. 21, no. 4, pp. 88-93, 2008.

[27] Z. Zheng, J. Lee, M. Saifuzzaman, and J. Sun, "Exploring association between perceived importance of travel/traffic information and travel behaviour in natural disasters: a case 
study of the 2011 Brisbane floods," Transportation Research Part C: Emerging Technologies, vol. 51, pp. 243-259, 2015.

[28] Z. Feng, M. Yang, W. Zhang, Y. Du, and H. Bai, "Effect of longitudinal slope of urban underpass tunnels on drivers' heart rate and speed: a study based on a real vehicle experiment," Tunnelling and Underground Space Technology, vol. 81 , pp. 525-533, 2018. 